\title{
Investigation of Strain Gages for Use at
}

\section{Cryogenic Temperatures}

\author{
Paper reports the results of an investigation undertaken to study \\ the performance characteristics of a number of commercially available strain gages \\ from room temperature to $36^{\circ} \mathrm{R}$ and for resistance measurements to $7^{\circ} \mathrm{R}$
}

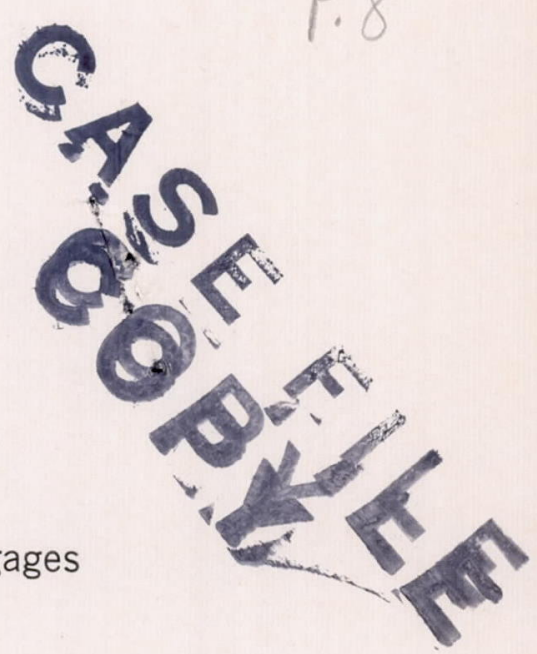

by Albert Kaufman

\begin{abstract}
Strain sensitivity and resistance changes in Advance, Karma, Budd Alloy, Nichrome V, and stabilized Armour D foil gages, and Nichrome V-platinum temperature-compensated gages were evaluated at cryogenic temperatures. The more promising gage types, as determined from these studies, were tested to strain levels up to $11,000 \mu \mathrm{in}$./in. with tensile specimens. The other performance characteristics that were investigated included zero drift, creep, hysteresis, linearity and gage element size effects. A mounting method developed for foil gages to be used at cryogenic temperatures is described.
\end{abstract}

\section{Introduction}

High specific-impulse cryogenic liquid propellants with boiling points as low as $36^{\circ} \mathrm{R}$ are being used increasingly in space vehicles. Because of the combination of thermal, pressurization, inertial and bending effects to which these vehicles are subjected, the stress distributions are often highly complex. They do not always lend themselves to theoretical analysis and it then becomes desirable to measure the strains experimentally by using electrical-resistance strain gages. The information that has been available on the performance of strain gages at cryogenic temperatures has usually not extended below $139^{\circ} \mathrm{R}$, the boiling point of liquid nitrogen at a pressure of 1 atm.

This paper reports the results of an investigation undertaken at the Lewis Research Center of the NASA to study the performance characteristics of a number of commercially available strain gages from room temperature to $36^{\circ} \mathrm{R}$ (the boiling point of liquid hydrogen at 1 atm.) and for resistance measurements to $7^{\circ} \mathrm{R}$ (the boiling point of liquid helium at $1 \mathrm{~atm}$.). The gages that were studied were Advance, Karma, Budd Alloy, Nichrome V, stabilized Armour D foil gages, and Nichrome V-platinum temperature-compensated foil gages.

Albert Kaufman is Aerospace Engineer, Lewis Research Center, National Aeronautic and Space Administration, Cleveland, Ohio.

Paper was presented at 1963 SESA Spring Meeting held in Seattle, Wash., on May 8-10.

\section{Apparatus and Procedure}

\section{Method of Mounting Foil Gages and Instrumentation}

The surface of the material was first prepared by lightly abrading it with an air-abrasive unit. The surface was then sprayed with GA-5 epoxy cement to a thickness of about 1 mil. This precoat was allowed to set for $4 \mathrm{hr}$ at room temperature and then was cured at $175^{\circ} \mathrm{F}$ for $16 \mathrm{hr}$. A light mounting coat of cement was then sprayed over the precoat. If the foil gage had a strippable backing, this was removed and the bare gage was embedded in the cement. The gage was then clamped to the specimen with silicone-rubber pads under a pressure of about 5 psi. The backings of the Advance and Nichrome $\mathrm{V}$-platinum gages were not strippable. In these cases, the gage, with its backing, was embedded in the cement and clamped. The cement was again cured at $175^{\circ} \mathrm{F}$ for $16 \mathrm{hr}$. Lead wires were then soldered and an overcoat of cement less than $1 \mathrm{mil}$ was sprayed over the whole assembly. Some difficulty was encountered in obtaining good soldered connections with the stabilized Armour D gages; in some instances, the leads were welded to the gage terminals. After the overcoat had been added, the curing cycle was repeated. The towl mount thickness was kept about 2 mils to avoid cracking and to minimize crazing of the cement at high strains in the cryogenic environment. If the precoat thickness was under 1 mil, however, electrical grounds were likely to occur.

Teflon-insulated silver-coated copper wires of 26 gage were used for the portion of the wiring inside the cryogenic bath. These were soldered to copper tabs cemented on the specimens which were, in turn, connected with copper lead wire to the gage terminals.

The compensating arm of the Wheatstone-bridge circuit consisted of a dummy gage of the same type as the active gage, mounted on the same material and exposed to the same temperature environment. The 


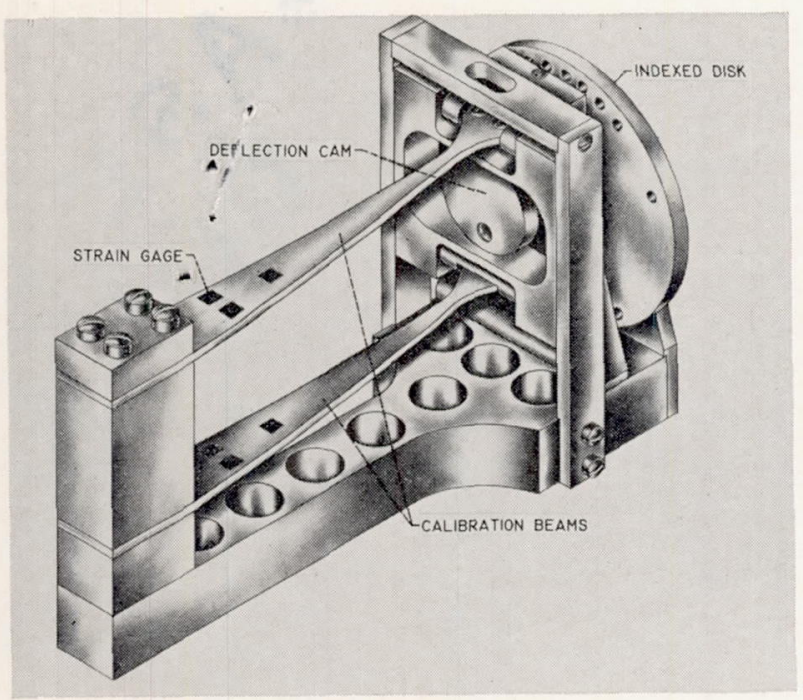

Fig. 1-Strain-gage calibrator

one exception to this was the Nichrome V-platinum temperature-compensated gage type. For these gages, ballast resistors, as recommended by the manufacturer, were placed in series with the platinum-compensating elements.

A multiwire circuit was used to eliminate possible errors due to temperature-induced resistance changes in the lead wires. The gage outputs were read on a $\mathrm{B} \& \mathrm{~F}$ multichannel strain-gage recorder.

\section{Measurement of Strain-sensitivity Changes}

Changes in the strain sensitivities of the gages under cryogenic conditions as compared to room temperature were measured by mounting the gages on cantilever-beam specimens and testing them with the strain-gage calibrator shown in Fig. 1. The specimens were $71 / 2$ in. long by 0.15 in. thick. The width was linearly tapered for constant strain over a 5-in.long test section. All the calibrator-beam specimens for testing foil gages were fabricated from 2014-T6 aluminum alloy. Two specimens at one time were tested in the calibrator. Generally, 3 pairs of gages were mounted back-to-back on a specimen. In cases where the elements were large, only one or two gages were moit red on a side.

The free encis of the beams were deflected through the movement $\&$ an eccentric cam. The cam moved vertically a block to which the specimens were pinned. This block was restrained only by the cam and the frame in order to avoid extraneous longitudinal loading on the specimens. An indexed disk attached to the cam was used to obtain the desired deflection and to lock the calibrator. The latter was done through a spring-loaded tapered pin that entered one of the tapered holes on the indexed disk.

The positions on the disk were designed to impose deflections from 0 to $1 / 2$ and 0 to $-1 / 2$ in. in $1 / 8$ in. increments. At maximum or minimum deflection, the magnitude of the strain was about $2000 \mu \mathrm{in}$./in.

The calibrator was placed in a liquid-hydrogen cryostat. The indexed disk and the locking device were manually operated through shafts coming out of the cryostat. The top of the cryostat was covered with styrofoam and sealed with a calking compound before a tesit. Temperatures were measured with a platinum-wire thermocouple attached to the calibrator.

Calibrator tests were made in liquid nitrogen and

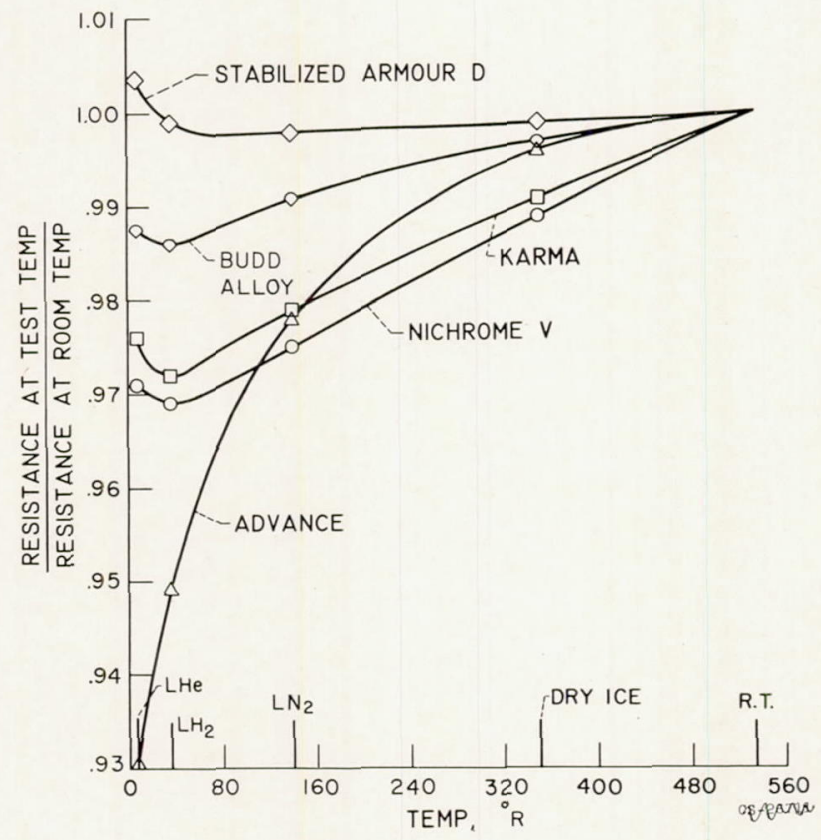

Fig. 2-Resistance ratio as a function of temperature

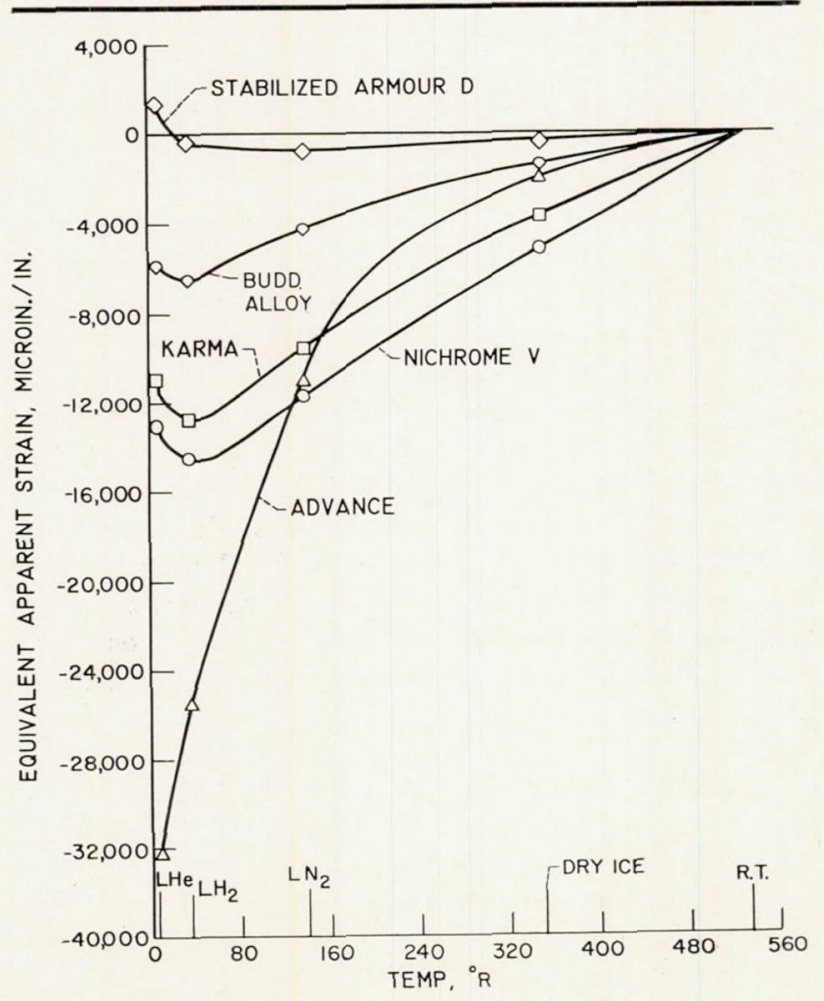

Fig. 3-Equivalent apparent strain as a function of temperature 


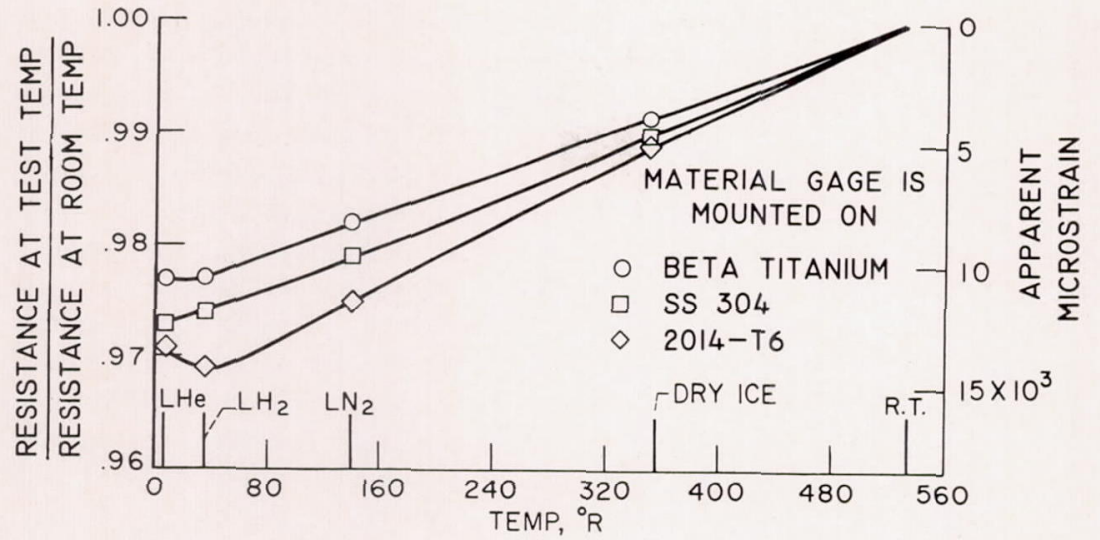

Fis. 4-Resistance ratio as a function of temperature for Nichrome $V$ gages mounted on various materials

liquid hydrogen. Room-temperature tests were made before and after each cryogenic test to determine any changes in the strains measured at room temperature after immersion in the cryogenic baths; no such changes were ever detected. In each test, the beams were put through three deflection cycles, and the results were averaged. The calibrator tests were only used to find changes in strain sensitivity at cryogenic temperatures as compared to room temperature and not to measure the magnitude of the gage factors. The strain-gage recorder was set for the gage factor published by the manufacturer.

A program was set up on an IBM 7090 computer that corrected the data for zero drift, checked linearity and computed the equations of the best straight lines through the data by the method of least mean squares. Tension and compression data were treated separately.

\section{Tensile Tests to Higher Strains}

In order to test the more promising gage types (as determined from the calibrator tests) to higher strain levels, gages were mounted on tensile specimens of beta-titanium alloy $(13 \mathrm{~V}-11 \mathrm{Cr}-3 \mathrm{Al}-\mathrm{Ti})$ and tested in liquid hydrogen. This alloy was used because, in liquid hydrogen, the linear portion of the stress-strain curve extends to extremely high strains. The specimens were $3 / 8$ by $1 / 8$ in. in cross section with a 2 -in.-long test section. Two gages were mounted back-to-back on each specimen. The same instrumentation as in the calibrator tests was used. In these tests a snap-on extensometer of the linear variable-differential transformer type and of 1-in. gage length was mounted over one of the strain gages. This extensometer was calibrated for use in liquid hydrogen with a micrometer-driven calibration device.

\section{Results}

\section{Resistance Measurements}

Resistance measurements were made on two gages of each type at room temperature, in dry ice $\left(350^{\circ}\right.$ $\mathrm{R})$, liquid nitrogen $\left(139^{\circ} \mathrm{R}\right)$, liquid hydrogen $\left(36^{\circ}\right.$ $\mathrm{R})$, and liquid helium $\left(7^{\circ} \mathrm{R}\right)$. In Fig. 2 the ratio of the resistance at the cryogenic temperature to that at room temperature is plotted as a function of temperature. All the foil gages were mounted on 2014-T6 aluminum alloy. About 1 ma was put through the gages for these measurements.

The best resistance stability was attained with stabilized Armour D, which changed less than 0.5 percent over a temperature range from 534 to $7^{\circ} \mathrm{R}$. In liquid hydrogen the resistance was only 0.1 percent less than at room temperature. All the curves in Fig. 2 except for the Advance alloy showed a recovery in resistance at extremely low temperatures. For stabilized Armour D, this recovery began from the liquid-nitrogen environment, for the others from liquid hydrogen. No change in room-temperature resistance, because of immersion in the cryogenic fluids, was observed for any of the gages. The resistance-ratio curves for Nichrome $\mathrm{V}$ gages from two different sources were virtually identical.

The resistance data were converted to equivalent apparent strain by using the published gage factors and plotted as a function of temperature in Fig. 3. The stabilized Armour D showed an apparent strain of $800 \mu \mathrm{in}$./in. from room to liquid-nitrogen temperature and of about $400 \mu \mathrm{in}$./in. to liquid-hydrogen temperature. The next most stable alloy, Budd, would show an equivalent apparent strain of about $6000 \mu \mathrm{in}$./in. in cooling to these temperatures. The resistance change for Advance in the region from liquid-nitrogen to liquid-helium temperatures is so large as to make it unsuitable for cryogenic applications under any condition. In ticuid hydrogen, a temperature change of $1^{\circ} \mathrm{R}$ would cause an equiv alent apparent-strain change of $200 \mu \mathrm{in}$./in. The apparent strains for the Nichrome $\dot{V}$-platinum temperature-compensated gages depend on the ballast resistances that are used.

The effect on the gage resistance at cryogenic temperatures of mounting gages on different materials is shown in Fig. 4 for Nichrome $\mathrm{V}$ foil gages mounted on aluminum, stainless steel, and titanium alloy. The maximum total-resistance change was about 3 percent from 534 to $7^{\circ} \mathrm{R}$. The difference between the three curves in liquid hydrogen is less than 1 percent; however, this represents a difference of about $3000 \mu \mathrm{in}$./in. in liquid hydrogen between the aluminum and titanium curves. Thus, in the measure- 
ment of thermal strains across a cryogenic-temperature gradient, the effect of the thermal coefficient of expansion of the material on which the gage is mounted has to be taken into account.

Figure 4 also indicates that the gages mounted on the stainless steel and titanium alloys do not show the same degree of recovery in resistance at extremely low temperatures as those mounted on aluminum. This would indicate that the upswing in the curves is due not to resistivity changes occurring in the gage alloy itself but to changes in the relative thermal contractions between the gages and the materials on which they are mounted.

\section{Strain-sensitivity Changes}

Table 1 shows the gage alloys, element sizes, and sample sizes used in the strain-gage calibrator tests. The two Nichrome $V$ gages came from different sources, the stabilized Armour D gages from the same source.

The results from the calibrator tests are shown in Fig. 5 where the strain-sensitivity ratio (the ratio of the gage factor ąt the test temperature to the gage factor at room temperature) is plotted as a function of temperature. The Nichrome $\mathrm{V}$ and stabilized Armour D curves represent an average of all gages of the type that were tested regardless of size.

The smallest change in strain sensitivity at cryogenic temperatures was shown by the Nichrome $\mathrm{V}$ alloy. In liquid nitrogen and hydrogen the strainsensitivity change from room temperature was less than 0.5 percent. Of the 10 Nichrome $\mathrm{V}$ gages that were tested, the maximum variation from these curves was 2 percent. The Nichrome V-platinum temperature-compensated gage showed a strainsensitivity change of 6 percent in liquid hydrogen. Since the magnitude of this change was unlikely to be due to the Nichrome $\mathrm{V}$, it is probable that thermal effects in the platinum-compensating element were affecting the strain sensitivity of the composite gage. Two of the gages failed at the weld junction between the Nichrome $\mathrm{V}$ and platinum elements during the tests.

TABLE 1-SUMMARY OF GAGES TESTED

IN CALIBRATOR

[Beam Material, 2014-T6]

\begin{tabular}{|c|c|c|c|c|}
\hline $\begin{array}{l}\text { Gage } \\
\text { material }\end{array}$ & Gage type & $\begin{array}{l}\text { Gage ele } \\
\text { Width, } \\
\text { in. }\end{array}$ & $\begin{array}{l}\text { Lent size } \\
\text { ingth, }\end{array}$ & $\begin{array}{c}\text { Number } \\
\text { of } \\
\text { gages }\end{array}$ \\
\hline Advance & Foil & 0.250 & 0.125 & 4 \\
\hline Karma & Foil & 0.250 & 0.125 & 4 \\
\hline Budd & Foil & 0.250 & 0.125 & 4 \\
\hline \multirow[t]{2}{*}{ Nichrome V } & Foil & 0.250 & 0.125 & 6 \\
\hline & Foil & 0.18 & 0.17 & 4 \\
\hline (Platinum) & $\begin{array}{l}\text { Temperature } \\
\text { compensated }\end{array}$ & 0.39 & 0.50 & $4^{*}$ \\
\hline Stabilized & Foil & 0.125 & 0.0625 & 2 \\
\hline \multirow[t]{2}{*}{ Armour D } & Foil & 0.250 & 0.125 & 6 \\
\hline & Foil & 0.500 & 0.500 & 2 \\
\hline
\end{tabular}

There seems little reason to consider the Karma, Budd, or Advance alloys for cryogenic applications because of the large changes in strain sensitivity shown in Fig. 5 and in resistance in Fig. 2. The Advance alloy shows a 3 percent decrease in strain sensitivity from room temperature down to liquid nitrogen. Below this temperature, the strainsensitivity change was considerably larger. An undesirable characteristic of the Advance alloy was the large amount of data scatter between different gages and repeated tests of the same gages in liquid hydrogen. Of the four Advance gages that were tested, the variation from the curves of Fig. 5 was up to 6 percent. This variation is probably due to the extreme sensitivity of this alloy to slight temperature changes in this range. Even though the gage factor increases 6 percent in liquid hydrogen, the Nichrome $\mathrm{V}$-platinum temperature-compensated gage might prove useful for measuring thermal strains at low temperatures.

Second only to Nichrome V, stabilized Armour D alloy exhibited the least change in strain sensitivity in liquid hydrogen. The most noteworthy feature of this material (Fig. 5) is the large difference between the curves for tensile and compressive strain-sensitivity ratios. The strain sensitivity in liquid hydrogen as compared to room temperature increased $1 \frac{1}{2}$ percent for compression and decreased about 4 percent for tension.

This change in strain sensitivity is also apparent in Fig. 6 where the results of calibrator tests on a typical stabilized Armour D gage at room temperature and

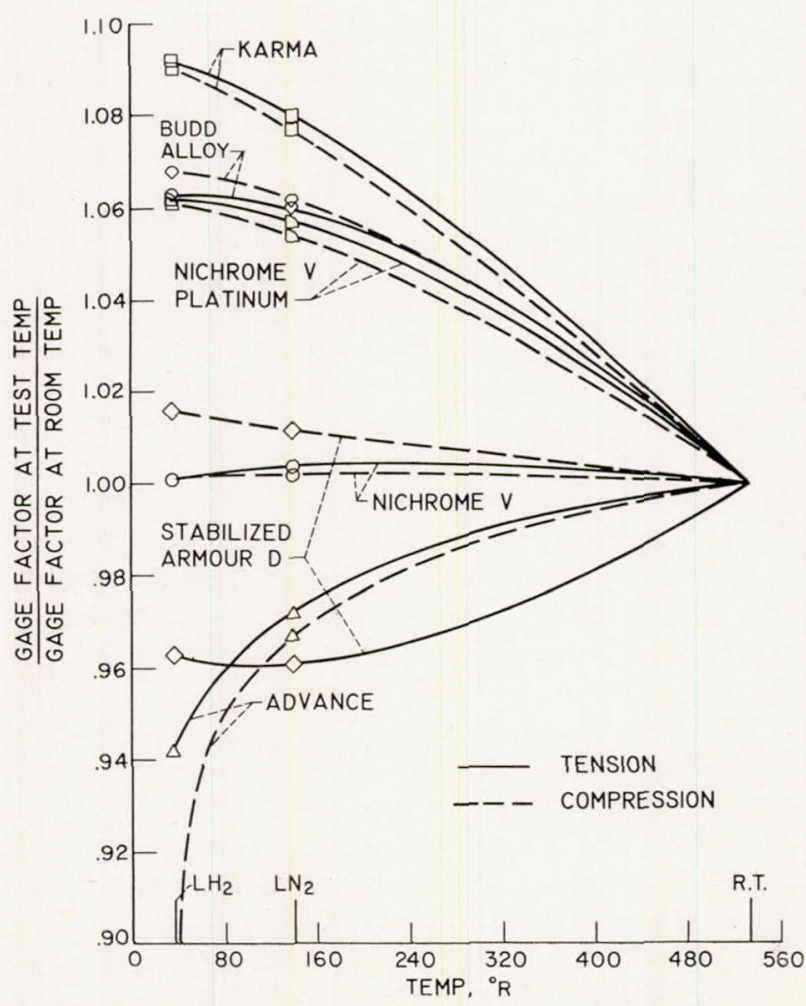

Fig. 5-Strain-sensitivity ratio as a function of temperature 


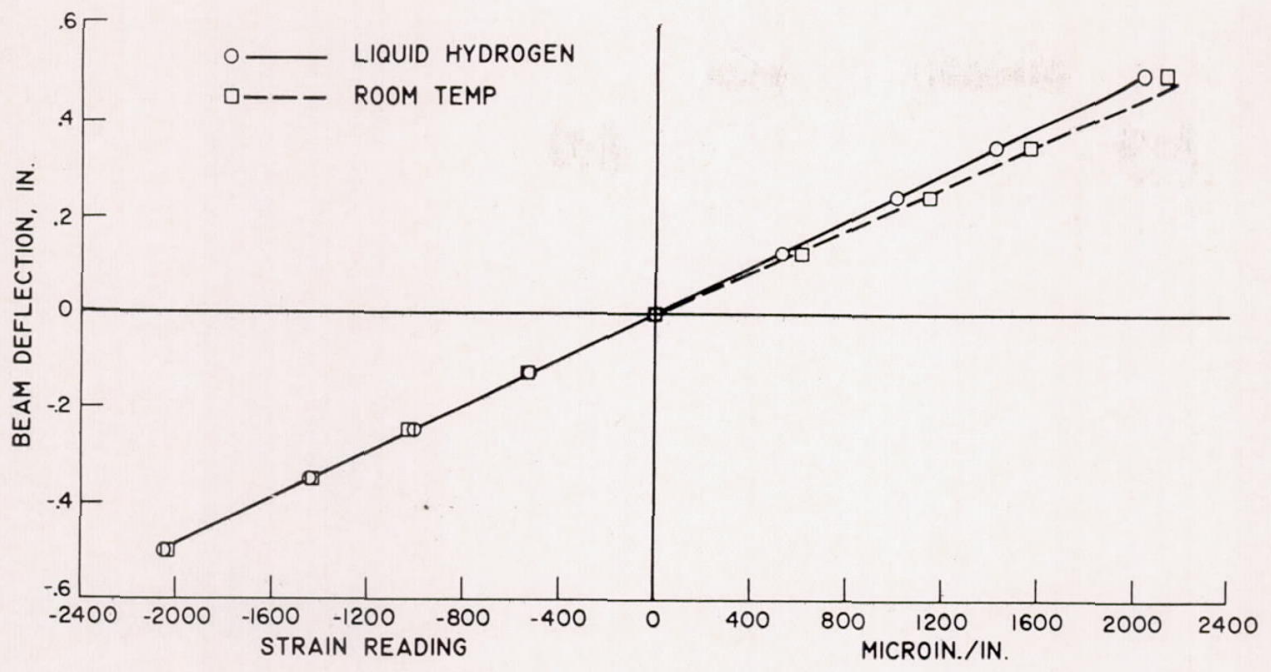

Fig. 6-Strain reading as a function of deflection for a typical stabilized Armour D gage on a calibrator-beam specimen

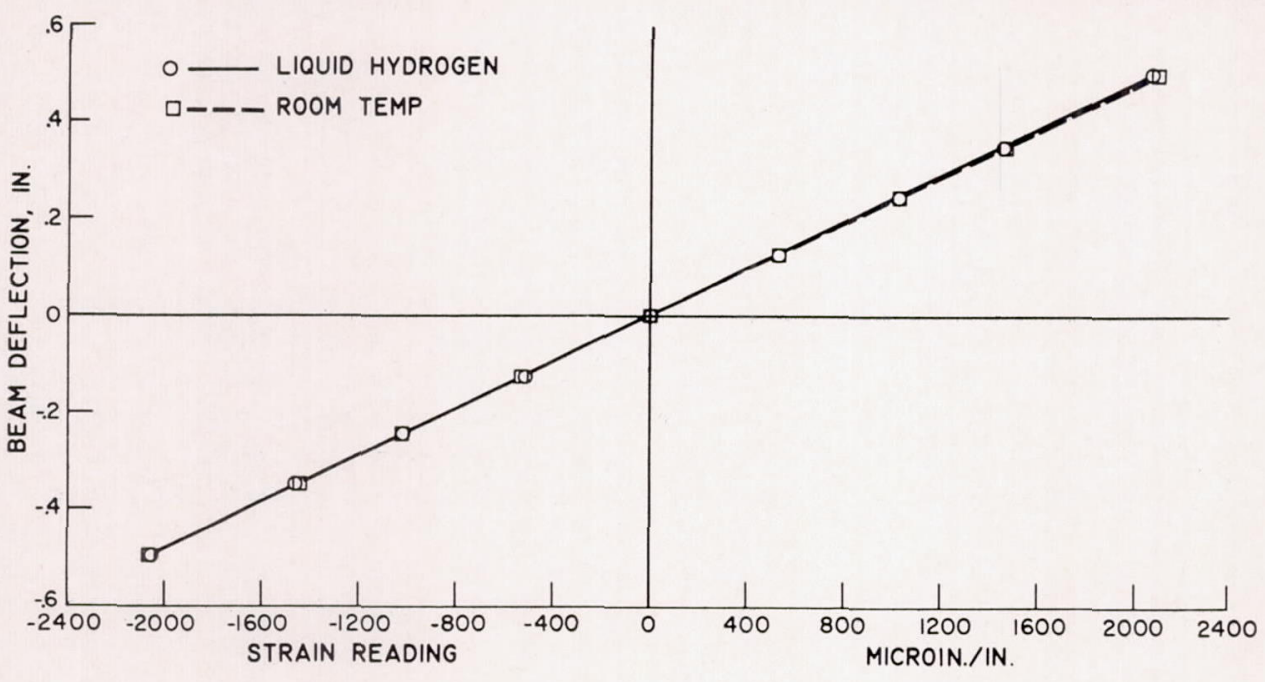

Fig. 7-Strain reading as a function of deflection for a typical Nichrome $V$ gage on a calibratorbeam specimen

in liquid hydrogen are shown. The liquid-hydrogen data had excellent linearity, and lines through these data showed about the same slope in both quadrants; this means that the gage factors in tension and compression are almost the same. At room temperature, there was also good linearity through the compression data, and the slope of a line through these data was within 1 percent of the compression slope in liquid hydrogen. On the tension side, the linearity was fairly good from 0 to $3 / 8$-in. deflection, but the $1 /{ }_{2}$-in. deflection deviated completely. This occurred in all tests of all stabilized Armour D gages that were tested at room temperature including different gage sizes and is not believed to be the result of experimental error. Although the linearity of the stabilized Armour D data improved as the temperature was decreased, there were still cases in which some nonlinearity was exhibited in liquid hydrogen. At room temperature, there was a significant difference in the slopes of the data in tension and compression up to a strain of $2000 \mu \mathrm{in}$./in. This was the main reason for the discrepancy between the tensile and compressive strain-sensitivity ratios of Fig. 5 .
Similar data for the calibrator test of a typical Nichrome $\mathrm{V}$ gage are presented in Fig. 7. The linearity of the data was good, and the slopes were almost identical in tension and compression. The difference between the room-temperature and liquidhydrogen-temperature results was negligible.

The effect of gage-element size on the strain-sensitivity change at cryogenic "tomperatures was studied by testing three different sizes of stabilized Armour D gages in the calibrator. In Fig. 8, the results of testing these gages to $\pm 2000 \mu \mathrm{in}$./in. in liquid hydrogen are shown. There was little size effect on the tensile strain-sensitivity ratio; for all three gage sizes it varied from 0.960 to 0.968 . There appeared to be some effect, however, for compressive strains. The strain-sensitivity ratio decreased from 1.032 to 1.001 as the gage size increased from $1 / 8$-in. width and $1 / 16^{-i n}$. length to $1 / 2$ by $1 / 2$ in. No clearcut size effect was found when these same gages were tested in liquid nitrogen.

The two types of Nichrome $\mathrm{V}$ gages showed almost identical strain-sensitivity changes. Since the areas of the two gages were almost the same, the size ef- 


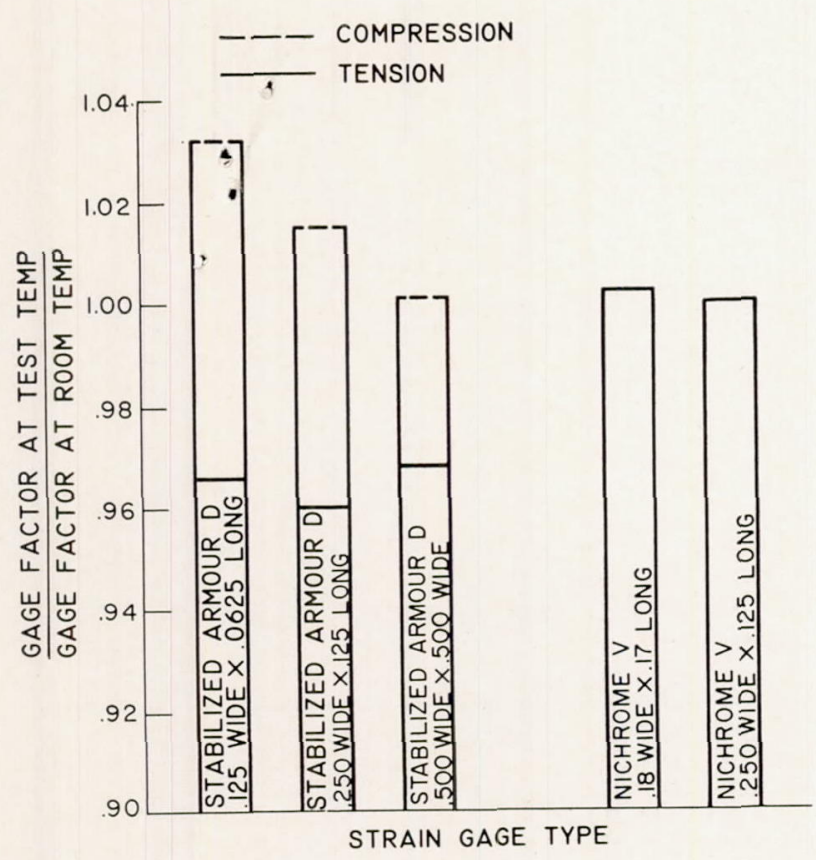

Fig. 8-SIze effect on strain-sensitivity ratio for stabilized Armour $D$ and Nichrome $V$ gages in liquid hydrogen

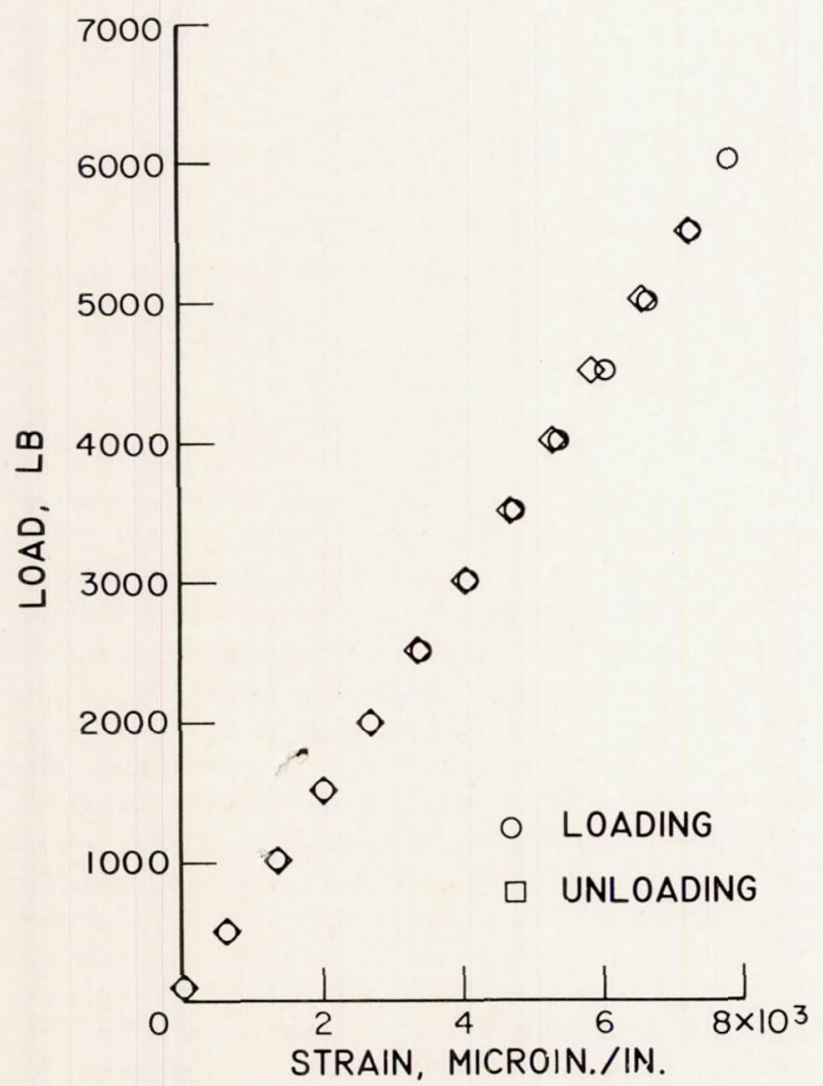

Fig. 9-Hysteresis effect for a stabilized Armour $D$ gage on a beta-titanium tensile specimen in liquid hydrogen

fect for Nichrome V is not apparent. Neither of the Nichrome V types showed any difference in strain sensitivity between tension and compression.

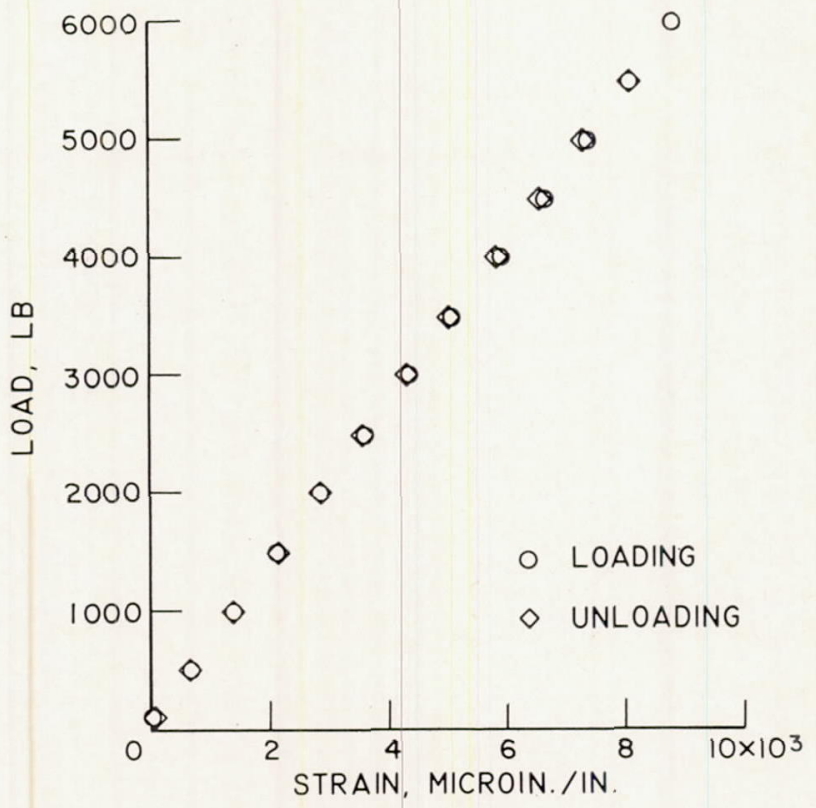

Fig. 10-Hysteresis effect for a Nichrome $V$ gage on a betatitanium tensile specimen in liquid hydrogen

\section{Creep, Zero-drift and Hysteresis Effects}

The effect of zero drift and creep on strain gages in a cryogenic environment was investigated by holding the beams in the calibrator at given deflections for $1 / 2 \mathrm{hr}$ and taking readings every $5 \mathrm{~min}$. Except for the Advance gages, the drift was minor. The maximum drift measured over the half-hour period in liquid hydrogen for the Nichrome $\mathrm{V}$ and stabilized Armour D gages was $8 \mu \mathrm{in}$./in. at 0 strain and 16 $\mu \mathrm{in}$./in. at a 2000- $\mu$ in./in. strain level. Drift of as much as $200 \mu \mathrm{in}$./in. was measured for Advance gages in liquid hydrogen.

Hysteresis effects were studied by mounting gages on tensile specimens of beta titanium and testing them in liquid hydrogen. A typical loading and unloading curve for a stabilized Armour D gage is shown in Fig. 9. The hysteresis effect on unloading from an 8000- $\mu$ in./in. strain level was about 2 percent. A similar curve for a Nichrome $\mathrm{V}$ gage is shown in Fig. 10. The hysteresis effect up to 8800 $\mu \mathrm{in}$./in. was less than 1 percent.

\section{Measurement of Large Tensile Strains}

The gage factors for a number of Nichrome $\mathrm{V}$ and stabilized Armour D gages were checked by mounting the gages and an extensometer on beta-titanium tensile specimens and loading the specimens to strain levels of about $4000 \mu \mathrm{in}$./in. at room temperature. Of 10 Nichrome $\mathrm{V}$ gages that were checked, the maximum variation from the published gage factors was 3.3 percent, while, for eight stabilized Armour $\mathrm{D}$ gages, the maximum variation was 4.7 percent. Because of the nonlinearity effect with the stabilized Armour D gages at room temperature, the gage factor depends somewhat on the strain range over which it is evaluated. 


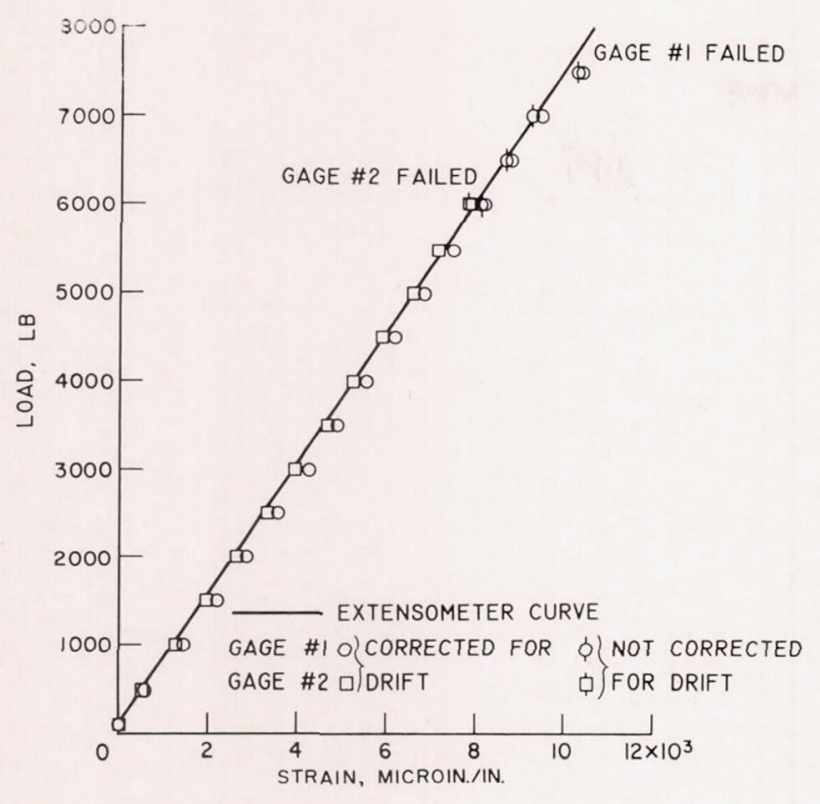

Fig. 11-Load against strain for stabilized Armour D gages on a beta-titanium tensile specimen in liquid hydrogen

The results of a test on a pair of stabilized Armour $\mathrm{D}$ gages mounted on a beta-titanium specimen immersed in liquid hydrogen are shown in Fig. 11. The test was accomplished by cycling the specimen between a preload of $100 \mathrm{lb}$ and each load level. The load levels were increased in increments of $500 \mathrm{lb}$. The data were corrected for the drift during each cycle. Uncorrected data (data with no correction for the drift from the start of the test) are also shown for load levels above $6000 \mathrm{lb}$. The gage factor published by the manufacturer was used in calculating the strain from the gage output. Some nonlinearity was present in both gages in the liquid hydrogen. Since the extensometer curve in Fig. 11 was a straight line, the nonlinearity was not believed to be caused by bending effects. At $2000 \mathrm{lb}$, the average strain from the gages was 5 percent greater than the extensometer strain; at $4000 \mathrm{lb}$ it was 3 percent greater; and, at $6000 \mathrm{lb}$, within 1 percent. Both gages failed because of breaks in the elements, one at $8000 \mu \mathrm{in}$./in. strain and the other at about 10,000 $\mu \mathrm{in}$./in. At a corrected strain level of $9400 \mu \mathrm{in}$./in., gage 1 showed a drift of about $200 \mu \mathrm{in}$./in. or about 2 percent over a period of nearly 2 hours.

The results for a similar test of a pair of Nichrome $\mathrm{V}$ gages in liquid hydrogen are shown in Fig. 12. The linearity of the data and the agreement with the extensometer curve were very good. The gages were tested to 11,000- $\mu$ in./in. strain without failure. At the end of the test, the cement bond still appeared in good condition except for some crazing of the overcoating. The total drift at 11,000- $\mu \mathrm{in}$./in. strain was 210 and $60 \mu \mathrm{in}$./in. for gages 1 and 2, respectively; this also occurred over a 2 -hr period.

\section{Conclusions}

The following conclusions were drawn from the in-

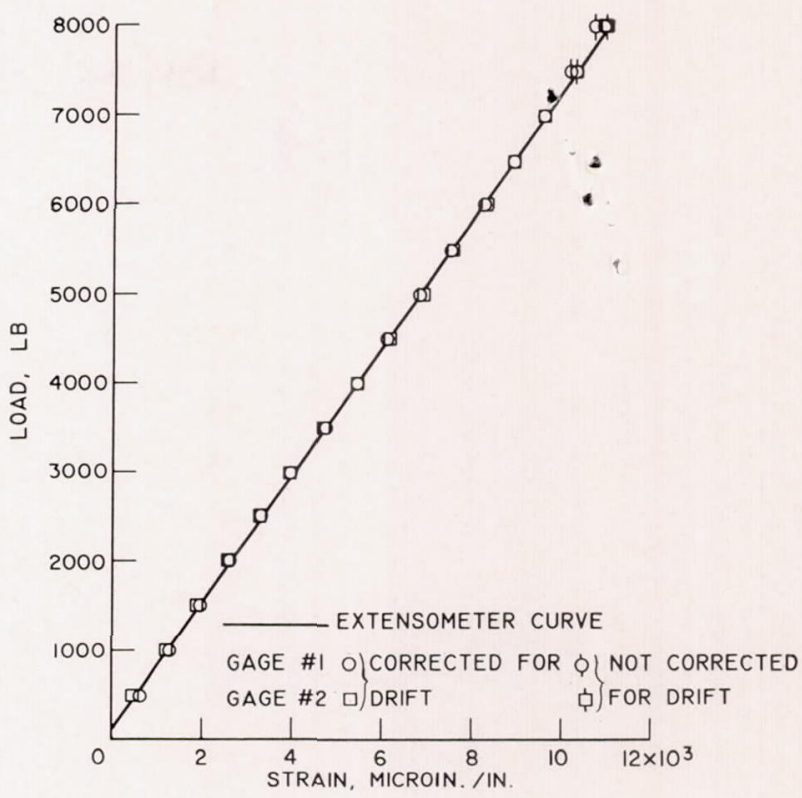

Fig 12-Load against strain for Nichrome $V$ gages on a betatitanium tensile specimen in liquid hydrogen

vestigation of the performance of electrical-resistance strain gages at cryogenic temperatures:

1. The most suitable gage alloy of those investigated for measuring strains in the cryogenic region, when no temperature-compensating dummy or gage with a temperature-compensating element can be used, is stabilized Armour D. After cooling from room temperature to liquid-hydrogen temperature, it showed an equivalent apparent strain of less than $400 \mu \mathrm{in}$./in. when mounted on aluminum. The strain sensitivity decreased about 4 percent in tension and increased about $1^{1 / 2}$ percent in compression from 534 to $36^{\circ} \mathrm{R}$. There was no effect of gageelement size on the tensile strain-sensitivity change. In compression, however, it appeared to decrease as the gage size increased. The linearity of the gages and the agreement with a calibrated extensometer at high strains in liquid hydrogen were adequate for general engineering purposes. Some gage failures occurred at strains from 8000 to $10,000 \mu \mathrm{in}$./in. Drift, creep and hysteresis effects were small.

2 . The most suitable gage allòy of those investigated for measuring strains at a constant cryogenic temperature is Nichrome V. No, difference was found in the performances of gages from two different sources. There was virtually no change in the strain sensitivity down to $36^{\circ} \mathrm{R}$. Gages were tested in liquid hydrogen to $11,000-\mu \mathrm{in}$./in. strain without failure. The linearity and agreement with extensometer data were very good. Drift, creep and hysteresis effects were small.

3. The mounting method for foil gages described in this paper produced cement bonds capable of taking at least 11,000- $\mu$ in./in. strain in liquid hydrogen. There was some crazing of the cement after exposure to these high strains at cryogenic temperatures. 